\title{
Betül İpşirli Argıt, Hayatlarının Çeşitli Safhalarında Harem-i Hümayun Cariyeleri 18. Yüzyıl, İstanbul: Kitap Yayınevi, 2017, 370 s. ISBN: 978-605-1051-67-3
}

\author{
Burçak Ersöz' @]
}

'Sorumlu yazar/Corresponding author: Burçak Ersöz (Doktora Öğrencisi), İstanbul Üniversitesi, Edebiyat Fakültesi, Tarih Bölümü, İstanbul, Türkiye E-posta: burcakersoz@yahoo.com ORCID: 0000-0002-3972-6920

Başvuru/Submitted: 15.07 .2020 Kabul/Accepted: 08.09.2020

Atıf/Citation: Ersoz, Burcak, "Betul Ipsirli Argit, Hayatlarının Çeşitli Safhalarında Harem-i Hümayun Cariyeleri 18. Yüzyll, Istanbul: Kitap Yayınevi, 2017" (Kitabiyat). Güney-Doğu Avrupa Araştırmaları Dergisi, 34 (2020), s. 125-131.

https://doi.org/10.26650/gaad.20213406

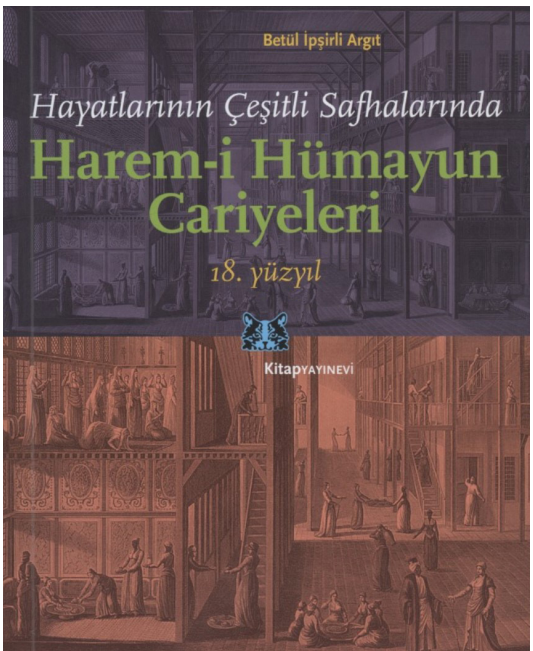


Hayatlarının Çeşitli Safhalarında Harem-i Hümayun Cariyeleri 18. Yüzyıl adlı kitap 2017 yılında Doç. Dr. Betül İpşirli Argıt tarafından kaleme alınmıştır. Kitap, yazarın 2009 yılında tamamlamış olduğu "Manumitted Female Slaves of the Ottoman Imperial Harem (Sarayîs) in Eighteenth-Century Istanbul/ Onsekizinci Yüzyıl İstanbulunda Osmanlı Saray Hareminden Çırağ Edilen Cariyeler (Sarayîs)" adlı doktora tezinin "genişletilmiş ve büyük ölçüde değiştirilmiş" (s. 9) halidir. Kitap, Topkapı Sarayı Harem-i Hümayun dairesindeki cariyelerin saraydaki görevleri, rolleri, statüleri, kurmuş oldukları ilişki ağları, saraydan ayrıldıktan sonraki yaşamları ile gittikleri yerlerde saray yaşamını ve kültürünü temsil etmeleri konularında yeni bilgiler sunmaktadır.

Kitabın odak noktası cariyelerin saraydaki yaşamlarından çok saraydan ayrıldıktan yani çırağ edildikten sonraki yaşamlarıdır. Çırağ sonrası yaşamları; evlilikleri, taşındıkları şehirler, oturdukları mahalleler, ilişkileri, gelirleri, mülkleri, eşyaları, hayır ve vakıfları üzerinden anlatılmaktadır. Yazarın bu anlatım esnasında çırağ edilmiş cariyelerin sarayla devam eden bağlarına ve ilişkilerine dikkat çekmesi, eserin literatüre önemli katkılarından biri olmuştur.

“Saray-ı Hümayundan muhrec, saray mu'takası, Sarayı Hümayun çırağlarından veya çırak” (s. 96) olarak adlandırılan saraylı cariyelerin incelenmesiyle Osmanlı hane yapılanması, hane ağları ve himaye ilişkileri ile bu yapılanmada sadakat konularına açıkık getirilmiştir. Yazar, kitabında imparatorluk hanesinden yapılan evliliklerin mevcut ilişki ağlarını kuvvetlendirdiği, yeni ilişkileri başlattığı, devlete sadakati geliştirdiği ve de toplumu sarayla tanıştırdığı iddialarını kuvvetlendiren örnekler sunmaktadır. Böylece kitapta saraylı olmanın anlamı ve kapsamı, haremdeki cariyelerin yaşamları üzerinden sorgulanmaktadır. Sarayın bu kadınların maddi ve kültürel dünyasını nasıl şekillendirdiği, yeni kurdukları ilişkilere ve topluma nasıl yansıdığı anlatılmakta ve Osmanlı hane yapılanmasının toplumdaki uzantılarına dair analizler yapılmaktadır.

Betül İpşirli Argıt bu kitabı ile hem Topkapı Sarayı Harem-i Hümayun dairesi üzerine yazılan literatüre hem de kadın ve biyografi çalışmalarına katkı sunmaktadır. Şu ana kadar yapılmış çalışmalar saray, valide sultan, padişah eşleri kadınlar, padişah kızları sultanlar ve cariyeler gibi birçok konudan bahsetmektedir. Literatür haremin teşkilat yapısı, valide sultan, valide sultanın haremdeki iktidarı ve siyasetteki rolü ile cariyelerin isimleri, kökenleri, görevleri, gelirleri üzerine yoğunlaşmakta, haremdeki kadınlara dair yeni biyografik çalışmalar da bulunmaktadır. Çağatay Uluçay'ın Harem ile Padişahın Kadınları ve Kızları, Leslie P. Peirce'in Harem-i Hümayun: Osmanlı Imparatorluğu'nda Hükümranlık ve Kadınlar, Ali Akyıldız'ın Mümin ve Müsrif Bir Padişah Kızı Refia Sultan ile Haremin Padişahı Valide Sultan: Harem'de Hayat ve Teşkilat, Lucienne Thys-Şenocak'ın Hadice Turhan Sultan Osmanlı Imparatorluğu'nda Kadın Baniler isimli çalışmaları ile daha birçok çalışma sayılabilir. Bu çalışmalar hem haremin teşkilat yapısı ile haremde yaşam ve düzeni anlatmaları bakımından hem de özelde haremde yaşayan kadınların biyografileri olarak önemlidirler. Ancak cariyeleri bütün olarak haremdeki faaliyetleriyle ilgili ele almak dışında birey olarak inceleyen, haremden ayrıldıktan sonraki yaşantıları ve ilişkileri hakkında bilgi veren çalışmalar bulunmamaktadır. Var olan literatürdeki 
bu eksiklik kitapta da belirtildiği gibi, bir anlamda hem cariyelerin birey oldukları gerçeğini gözden kaçırmakta hem de cariyelerin saraydan ayrıldıktan sonra saray ile bağlarının koptuğu gibi bir izlenim oluşmasına sebep olmaktadır (s. 35-36). Betül İpşirli Argıt, Hayatlarının Çeşitli Safhalarında Harem-i Hümayun Cariyeleri 18. Yüzyıl adlı kitabı ile literatürdeki bu boşluğu doldurmaktadır.

Yazar kitabında, cariyelerin sanılanın aksine çırağ edildikten sonra sarayla bağlarının kesilmediğini tam tersine ilişkilerinin yeni bir şekle bürünerek saltanat kurumunun temsilcisi olduklarını iddia etmektedir. Böylece merkeziyetçi bir devletin kurduğu sistemin topluma inen köklerine de açıklık getirmektedir. Diğer taraftan Harem-i Hümayun kurumunun Enderun kadar önemli olduğunu vurgulamakta ve her iki kurumun padişahın otoritesinin merkezde toplanmasını birlikte sağladıkları, bu yüzden bir bütünlük içinde değerlendirilmeleri gerektiğini savunmaktadır. Kitabın her bölümünde; Harem-i Hümayun'daki cariyeler ile ilgili uygulamaları açıklarken, Enderun'daki işleyiş hakkında da bilgi vererek okuyucuya iki kurumu kıyaslama, benzerlikleri tespit etme ve bütünlüğü görme imkânı sağlamakta, böylece Osmanlı saray araştırmalarına önemli bir katkı sunmaktadır.

Kitap, aynı zamanda saraylı kadınların yaşamlarının hem kölelik hem de azad sonrası dönemlerinin farklı yönlerini ele alması sebebiyle kölelik çalışmalarına katkı sunmaktadır. Cariyelerin saraya alınma yolları, seçilmeleri, isim değişiklikleri, eğitimleri, hizmetleri, çırağ edilmeleri, evlilikleri, çırağ sonrası sahipleri ile sosyal, hukuki ve ekonomik ilişkileri ile maddi dünyaları üzerinden Osmanl’da kölelik kurumuna dair uygulamaları örneklendirmektedir.

Yazar kitabında ikincil kaynakların yanı sıra 18. yüzyıla ait oldukça zengin ve birinci elden kaynakları kullanmıştır. İstanbul Şeriyye Sicilleri Arşivi başta olmak üzere Başbakanlık Osmanlı Arşivi, Topkapı Sarayı Müzesi Arşivi ile Vakıflar Genel Müdürlüğü Arşivi evrakları, Hobhouse, Thorntorn gibi seyahatnameleri, D'Ohsson, Lady Montagu gibi Avrupalı devletlerin İstanbul'da bulunan elçileri ve kişilerinin mektup ve raporları, Bobovius gibi Osmanlı Sarayı'nda hizmetli kişilerin eserleri, dönem tarihleri gibi çok fazla Osmanlı ve Avrupalı kaynaktan faydalanmaktadır. Özellikle harem ile ilgili yer yer abartı ifadelere sahip olan yabancı kaynakların tenkidine özen gösterilmiştir. Tüm bu kaynaklar ile sadece 18. yüzyıl değil 16 . yüzyıldan 19. yüzyıla kadar geniş bir zaman diliminde harem kurumunun ve uygulamalarının değerlendirilmesi ve farkı dönemlerde meydana gelen değişimlerin neler olduklarını belirlemek mümkün olmuştur. Kullandığı kaynaklar arasında Evkâf-ı Hümâyun Müfettişliği Mahkemesi'ne ait mahkeme kayıtları ile tereke defterleri önemli bir yer tutmaktadır. Yazar 18. yüzyılın ilk yarısı için 1714-1732 yılları arasından 385, yüzyılın ikinci yarısı için 1773-1775 yılları arasından 43 saraylı cariyeye ait kayıtlar üzerinden maddi dünyalarını, servetlerini, mallarını, evlilik, boşanma, mal alım-satım, borç ve ödünç alıp-verme, vasilik ve vakıflarla ilgili meselelerini değerlendirmektedir.

Argıt, kitabında prosopografi metodunu kullandığını ifade etmektedir. Bunun nedeni incelediği kaynaklardan bir cariyeye ait tam bir biyografi çalışması çıkarmanın mümkün ol- 
mamasıdır. Yazar, 800 saraylı kadının yaşamlarının belirleyici özelliklerinin tespit edilebildiği malzeme üzerinden, bu yaşamların benzeyen ve farklılaşan yönlerini dikkate alarak tüm zorluklarına rağmen bir grup biyografisi oluşturma gayretinde olduğunu, bununla birlikte bir kısmının yaşamının da, belgelerden ulaşılabildiği kadar, kısmen detaylandırılabildiğini vurgular (s. 52). Betül İpşirli Argıt tarafından yazılan Hayatlarının Çeşitli Safhalarında Harem-i Hümayun Cariyeleri 18. Yüzyıl adlı kitap toplamda altı ana bölümden oluşmaktadır.

Kitabın birinci bölümünde çırağ sonrası ilişkilerin temellerinin atıldığı harem dönemi incelenmekte, cariyelerin haremde ortak bir mekânda yaşamaları, birlikte eğitim almaları birbirlerine yakın rütbelerde görevlendirilmeleri, bu arada kurdukları iletişim ve bağın ileriki yıllardaki ilişkilerini nasıl belirlediği üzerinde durulmaktadır. Haremde kimlerin yaşadığının sınırları çizilmekte, haremdeki cariyeler gruplandırılmakta ve sarayda geçtikleri aşamalar anlatılmaktadır. Bu aşamalar ile haremdeki hiyerarşi detaylandırılmakta ve böylece harem içi iletişimin nasıl gerçekleştiği konusuna ışık tutulmaktadır. Cariyelerin haremdeki statüleri hem maddi dünyalarını hem haremdeki nüfus ve etki alanlarını hem de kimlerin maiyyetinde oldukları ve kendi maiyyetlerinde kimlerin bulunduğu üzerinden bağlantılarına dikkat çekilmektedir. Sonraki bölümlerde anlatılacak ilişki ağlarını temellendirmek amacıyla bir cariyenin kimin adabından geçtiği ve kime hizmette bulunduğunun önemi, haremde cariyelere verilen yeni isimleri ile eski kimliklerinden koparken saray terbiyesince eğitilmeleri üzerinden yeni bir kimliğe girişleri, bu aşamada cariyelerin aileleriyle bağlarının olup olmadığı konu edilmektedir. Ailesiyle bağı kopmuş cariyelerin haremde yeni bağlantılar kurarak sarayla aidiyet duygusu geliştirmelerinin hem haremde hem harem sonrası yaşamda hane yapılanmalarının gücünü anlamak açısından değerlendirilmesi de bu bölümün üzerinde durduğu konular arasındadır. Bir diğer konu haremde farklı mevkideki kişilerin cariye sahibi olmaları ve tüm maddi ilişkileri, himaye ilişkilerini şekillendirip, çeşitlendirmesi ve bağları güçlendirmesidir.

Kitabın ikinci bölümü cariyelerin saraydan çırağ edilerek ayrıldıkları döneme odaklanmaktadır. Çırağ sonrası sarayla ilişkilerinin devamlılı̆ını, ilişkiler üzerinden yaşamlarının şekillenişini ve ilişkiyi pekiştiren kanalları sorgulamaktadır. Maddi, manevi etkenleri, toplumsal ilişkileri, aidiyet duygusu ve hukuksal boyutları incelenerek ilişkilerin devamının tek bir yolla veya kişilere bağlı olmadığı ortaya konulmaktadır. Burada cariyelerin çırağlarında haremdeki statülerinin etkili olduğu vurgulanmakta ve saraydan çıkmanın genellikle evlilik anlamına geldiği belirtilmektedir.

Argıt, cariyelerin saray hizmetlerinin çırağ edilme sonrası etkilerini de ortaya koymaktadır. Gerek sarayla ilişkilerin gerekse cariye ile mevlası (sahibi) arasındaki ilişkinin nasıl dönüşüp devam ettiğini ve bu ilişki ağının haneye mensubiyeti beslediğini açıklamaktadır. Saraylı olmanın bir yandan da himaye edilmek anlamına geldiğini, çırağ sonrası sarayla devam eden ilişkilerle bu kadınların olası muhtelif sosyal ve ekonomik problemlere karşı sarayın güvencesine girdiklerini belirtmektedir. Kitapta saray içinde ortak bir mekân, birlikte geçen zamanlar ve alınan eğitimle birlikte oluşan kültür birliğinin ilişkilerin devamını nasıl sağladığı, ortak bir 
güç oluşturduğu ve bir gruba ait olma duygusu ile çırağ sonrası davranışlarda tüm bunların belirleyici olduğu üzerinden saray kültürünün topluma yayılma yolları gösterilmektedir. Saraylı kadınların ilişkilerinde, saraydan önce çıkan kadınların kendilerinden sonra çıkanlara yol göstermeleri, aralarında borç alıp verme ilişkileri olması, çırağ edilenler ile hâlâ sarayda olanlar arasında vekillik ve vasilik durumlarının ilişkilerini daha fazla kuvvetlendirmesi konuları ele alınmaktadır. Ele alınan konulardan bir diğeri de saraydan çırağ edilen kadınların sarayla olan bağlarının devamında hukukun bağlayıııı̆ı̆ının rolüdür.

Kitabın üçüncü bölümünde Argıt, saraydan çırağ edilen cariyelerin evliliklerini, sarayla bağın evliliklere yansıyan yönleri üzerinden incelemektedir. Bu evliliklerin hangi yolla gerçekleştiğini, cariyelerin haremdeki görevleriyle ilişkisini, evlendikleri kişilerin özelliklerini, evliliklerinin ne anlama geldiğini ve bazılarının yaptıkları ikinci evlilikleri konu edinmektedir. Yazar ikna edici bir biçimde ailelerinden kopuk olan saraylı kadınların çırağ sonrası evlilikler yolu ile himaye edilişleri ve sosyo-ekonomik açıdan yükselip, nasıl güç sahibi olabildikleri, sarayla devam eden ilişkileri ve kurdukları bağlar ile siyasi ilişkilerin bir parçası olma durumları ile sarayın nüfus ve gücünü temsil etmeleri üzerinde durmaktadır.

Argıt, saraydan çırağ edilen kadınlarla evlenen erkeklerin yüksek oranda seyfiye, ilmiye ve kalemiye sınıflarına veya sarayın Enderun ve Birun kısımlarında görevli askeri sınıfa mensup olduklarını tespit etmiştir. Burada haremdeki üst kademede görev yapan cariyelerin yüksek mevkideki erkeklerle evlendirildiklerini, Harem-i Hümayun ve Enderun'da saray adabı ve hanedana sadakat üzere eğitilen kişilerle yapılan evlilikler ile hanedana bağılı̆̆ın sağlandığını savunmaktadır. Bu evlilikleri Osmanlı hane yapılanması ve intisap ilişkilerinin önemi üzerinden değerlendirmektedir. Yazarın bu bölümde yapmış olduğu katkılardan biri de; sarayın gücünü temsil edecek yeni haneler oluşması ile çırağ edilen cariyelerin sosyal hayatlarındaki faaliyet ve ilişkilerin, sarayın toplum içindeki bağlantı kolları olarak işlev görerek siyasi mekanizmanın işleyişini etkilediklerini vurgulamasıdır.

Dördüncü bölümde Argıt, saraylı eski cariyelerin yerleştikleri mahalleleri ve buradaki toplumsal ilişkilerini incelemekte, saraylı kimliklerinin oturdukları mahallere etkisini göstermektedir. İkamet edilecek mahal seçiminde saraydan daha önce çırağ edilen kadınların yol göstericiliği olabildiği gibi hanedan kadınlarına ait sarayların bulunduğu mahallerin tercih edildiğini ya da evlenilen eşlerin saraya mensubiyetlerinin ve çalışma mahallerinin oturulacak yer açısından belirleyici olabildiğini ifade etmektedir.

Dördüncü bölümün dikkat çeken konularından biri de saraylı kadınların yaşadıkları toplumla kurmuş oldukları ilişkilerin sarayın toplumdaki imajına nasıl etki ettiğidir. Saraydan çırağ edilen kadınların yeni evlerinde ve kimi zaman yeni şehirlerinde topluma dahil oldukları, hem kendileri gibi saraylılarla hem de saraylı olmayan mahalle sakinleri ile ilişki kurdukları gösterilmektedir. Yazarın en önemli argümanlarından biri de bu ilişkilerin sosyalleşmenin ötesinde davalara da yansıyacak şekilde borç para alıp verme, şahitlik, vekillik ve vasilik gibi konularla çeşitlenmiş, toplumun saraylı kadınlar üzerinden sarayı tanımasına vesile olmuş olmasıdır. 
Yazar tüm bunları göstererek saray kültür ve adabının şehre ve imparatorluğa taşınmasında öncü olmalarının altını çizmektedir.

Kitabın beşinci bölümünde yazar, saraydan çırağ olmuş cariyelerin saray mensubiyetinin maddi varlık ve kaynaklarına etkisini değerlendirmektedir. Saraylıların servetleri arasındaki farkııı̆ı da haremdeki statü farkı ile açıklamaktadır. Sarayı kadınların bıraktıkları terekeleri aynı dönemde saraylı olmayan askeri statülü kadınlarınkiyle karşılaştırarak saraylı cariyelerin toplum içindeki konumlarını anlamayı kolaylaştırmaktadır. Tüm bunlarla dönemi daha iyi değerlendirme ve tanıma fırsatı sunulmaktadır. Saraylıların servet kaynaklarının sarayla olan bağı da ayrıca incelenmektedir. Cariyelerin haremdeki gelirleri ve çırağ sonrası kendilerine hibe edilen ev ve vakıf gelirleri dışında, evlendikleri kişilerin statüsü, gelir ve servetleri de bu konuda önemli bir etken olarak sunulmaktadır. Yazar, saraylı kadınların az bir kısmının çok yüksek servetlere sahip olduğunu tespit etmiştir. Saraylı kadınların gelirlerinin yüksekliğini eşlerinin meslek ve statüsünün belirlediği ve toplumda asker statülü kişilere yakın yüksek bir düzeyde yaşadıkları sonucuna varmıştır.

Bu bölümde saraylı cariyelere harem hizmetleri sırasında verilen hediyeler, çeyizler ile çırağ sonrasındaki hediyeleşmeler içinde yer alan kitap, saat, mücevher, kıyafet, köle, gayrimenkul ve değerli eşyaları ayrı ayrı dönemin saray kültürü açısından değerlendirilmiştir. Böylece açıklığa kavuşturulan konulardan bir başkası ise köle kökenli bu kadınların saray hizmetinde bulunmalarının onları belli bir statüye ve maddi varlığa da taşırken, bu varlık ve davranış biçimlerini ve sarayın günlük yaşam adabını hem İstanbul'un çeşitli semtlerine hem de taşraya taşıdıklarıdır.

Argıt, altıncı bölümde çırağ edilen saraylı kadınların saray ile ilişkilerinin devamlılığını yaptırdıkları vakıflar, vakıf çeşitleri ve vakıf ilişkileri üzerinden sorgulamaktadır. Saray ile miras ilişkilerinin saraylı cariyelerin yaptıkları hayır işlerinde etkili olduğunu ve bu kadınların vakıfların çeşidi konusunda hanedan kadınlarının izinden giderek pek çoğunun çeşme ve mektep yaptırdığını ortaya koymaktadır. Yazar ayrıca bu kadınların İstanbul ve imparatorluğun bazı yerlerinde mimari, kentsel, sosyal, dini ve kültürel gelişimi mütevazi de olsa desteklediklerini, tüm bunlarla halkın takdirini kazanmalarıyla mensup oldukları sarayın gücüne ve meşruiyetine de katkı sağladıklarını ifade etmektedir. Yazar burada saraylı cariyelerin halkın takdirini kazandıkları konusunda önemli bir iddia ortaya koymaktadır.

Saraylı kadınların kimi zaman diğer saray mensuplarının menfaat ve ihtiyaçlarını dikkate alarak mallarını vakfettiklerine, kimi saray mensuplarını yaptırdıkları vakıflarda vakıf yöneticisi olarak mütevelli ve nazır tayin ettiklerine kimi saray mensuplarının da kurdukları vakıflarının gelirlerinden istifa etmesini sağladıklarına değinmektedir. Kimi saraylıların mallarının üçte birini cariyelerine hibe edebildikleri, nakit paralarını saraydaki başka cariyelere ya da saray hizmetinde bulunan kişilere bağışladıkları tespitlerinde bulunmaktadır. Böylece saraylı kadınlar arasındaki dayanışmayı vakıfları üzerinden örneklendirmektedir. 
Sonuç olarak bu kitapta yazar, Osmanlı sarayına köle olarak giren cariye kadınların saray mensubiyeti ile belli bir maddi güce, ilişki ağlarına, mirasa, bir yaşam şekline, adaba ve duygu dünyasına sahip olduklarını, saraydan genellikle evlenerek çıktıktan sonra gittikleri yerlere ve ilişkilerine de saray yaşamı ve kültürünü yansıttıklarını detaylı bir şekilde anlatmaktadır. Kitaptan cariyeler arasında haremde başlayan saray-hane ilişkisinin tüm hayatları boyunca dönüşüp gelişerek devam ettiği hatta ölümlerinde mezar yerlerinin belirlenmesinde dahi etkili olması üzerinden sarayın köle kökenli bu cariyeleri hem hayatları boyunca himaye ettiği hem de çırağ edilen cariyeler üzerinden toplumda kendini ifade ettiği anlaşımaktadır.

Betül İpşirli Argıt'ın Harem-i Hümayun cariyelerinin çırağ sonrası yaşamlarııı daha önce hiç değinilmemiş yönleri ile ele aldığı Hayatlarının Çeşitli Safhalarında Harem-i Hümayun Cariyeleri 18. Yüzyıl adlı 2017 tarihinde yayınlanmış bu kitabı, Osmanlı saray ve harem çalışmaları ile kadın ve kısmen biyografi çalışmaları konusunda literatüre değerli bir katkı sunmaktadır. 
